\title{
Deepening Transformation Research and Performance Analysis of Higher Vocational Education Talent Cultivation Mode Guided by Expansion of Professional Engineering Quality
}

\author{
- Taking electromechanical integration as an example \\ Yao Jin, Feng Jing, Yao Xuan, Chen Licheng, Ye Meilin \\ College of Mechanical and Material Engineering, Wuzhou University, Wuzhou Guangxi, China
}

Keywords: professional engineering quality; higher vocational education; training mode deepening transformation

\begin{abstract}
This paper takes the current development direction of mechanical and electrical integration as a guide and points out some urgent problems in the cultivation of higher vocational education of mechatronics and puts forward several dimensions from the aspects of curriculum design, moral quality, humanistic quality cultivation and enterprise practice, and higher vocational education reform to strengthen professional continuing education, to build vocational professional quality-based vocational education training model and to form a complete set of higher vocational education personnel training, performance evaluation system and the corresponding evaluation methods.
\end{abstract}

\section{Professional Quality Development}

\subsection{Professional quality and its structure}

Quality refers to the intrinsic basic qualities of human beings that are inherent to the human body and that are relatively stable in terms of physical and personal qualities acquired through acquired training and education. Professional quality is a comprehensive manifestation of the understanding and adaptability of the social profession through the formation and development of laborers through education, labor practices, and self-cultivation. Professional quality is characterized by professionalism, stability, internality, integrity, and development.

Talent determines the lower limit, and professionalism determines the upper limit. Professional quality includes the following points: ideological and moral qualities include responsibility consciousness, political quality, enterprising spirit, hardworking style, and difficult work style.

\subsection{The connotation of professional quality standard}

Through the analysis of the information collected from the employment situation in the talent market in recent years, many employers insist on both morality and integrity, but the quality is placed first. Vocational education gradually builds its own characteristics of running a school goal and concept pursuit with ability-centered as its core but has not changed the core position of "utilitarian practical education" and still regards "limited value as the ultimate value of life". To solve this problem, this paper studies the connotation, goals and development trend of talent cultivation in higher vocational education in the future from the perspectives of quality, personality, ability, and knowledge standard.

\section{Analysis of Existing Problems in Training System of Higher Vocational Education}

Through the analysis, it is found that the current talent training in higher vocational education has the following problems, such as the setting of professional learning content and the skills required for the specific work performed after the work does not match, the talent training program does not meet the job requirements, intermediate vocational education and senior occupation the educational system of education is misplaced, the content of the learning course cannot be well 
connected, and the management cannot achieve standardized systems. The key to the successful integration of curriculum in the training of higher and higher vocational education is the key issue. The main problems in this area are as follows:

- Unbalanced architecture. Middle-level and senior vocational education form a corresponding curriculum system around their own education system, design and complete the corresponding teaching materials, resulting in some professional courses in the middle and higher vocational stage content duplication phenomenon. At the same time, there are still problems with duplication of vocational skills training in middle-level and senior vocational education. Even vocational skills training requires lower standards than those in secondary vocational schools.

- The implementation is behind. Although the national teaching documents require that the proportion of theoretical teaching and practical teaching in the higher vocational courses should be $1: 1$, in practical teaching, practical teaching is not sufficient due to limited practical teaching conditions.

-The evaluation mechanism is simple. Lack of systematic performance evaluation index system. The evaluation index system should be formulated according to the actual needs of educational management, and a scientific evaluation mechanism should be formed. One is the full coverage of assessment indicators. The second is the principle of targeting. The third is the combination of qualitative and quantitative assessment. In the assessment system design, we must quantify the assessment indicators as much as possible.

\section{Vocational Quality Standard Training Mode Construction of Higher Vocational Education}

The principle of professionalism is reflected in the curriculum objectives, and it needs to be targeted to specific occupations or jobs. It is reflected in the development of the curriculum, and is mainly related to the knowledge, ability, and personality quality of professional or professional positions; it is reflected in the main body of curriculum construction.

- Professional basic quality module. The professional basic quality module measures the effectiveness and number of students' learning through "gross point" and "credits". Based on this, it conducts course study assessment and design graduation standard requirements, forming a comprehensive teaching management system with the core of credits. How to realize the dynamic real-time updating of functions such as credit entry, registration, and event planning through remote control improves the efficiency and quality of the activity curriculum.

-Professional Orientation Module. The first is the direction of intelligence. The "intelligent" mentioned here is a description of machine behavior. AI chips and intelligent algorithms give mechatronic products a level of intelligence. The second is that there are many upstream and downstream industrial chain manufacturers for mechatronics production, and there is no unified standard. Therefore, modularization is the development direction.

-Humanities quality training module. Carry out rich and colorful moral education activities and strengthen the "One-time sports activity is a kind of quality education, one theme class meeting is a bowl of 'spirit chicken soup'" moral education concept, in line with the principle of "teaching books first, educating people first" We will continue to strengthen moral education and introduce socialist core values in our classrooms. We will build effective student activities such as learning Lei Feng to do good things, performing arts, legal education, public welfare activities, and red education.

- Business Practice Module. Vocational education precisely combines specific industries and the needs of the labor market. Students, vocational education schools and enterprises have formed an organic unified exchange mechanism. Innovative use of "modern teacher-adult system", through joint teaching of schools and enterprises, in addition to tailored training needs for teachers and institutions, so that higher vocational teachers in-depth study of practical technology, led students to participate in business practice.

- Continuing Education Module. Accelerating the implementation of professional and technical personnel knowledge renewal projects requires a continuing education module. With the development of the times, knowledge innovation and fostering craftsmen's demand for higher vocational education continue to promote continuing education. 


\section{Analysis of Talents Training Performance in Higher Vocational Education}

(1) Mechatronics professional training. In order to strengthen the students' ability to connect theories in practice, we should gradually increase the proportion of case teaching in teaching and train students to find problems and analyze and solve problems. Through the employment of experts in related professional fields, first-line technicians, etc. to set up on-site teaching courses, and a comprehensive assessment of student learning results. The credit system is implemented, and the total credit is not less than 40 credits. Strengthen the practical practice of industry enterprises, set up a dual mentors or tutors group work system, give full play to the role of collective education, properly require government-related personnel to participate in the guidance of student papers, and pay attention to and strengthen the cultivation of political ideology and professional ethics.

(2) Performance evaluation body. Performance evaluation body structure as shown in Figure 1

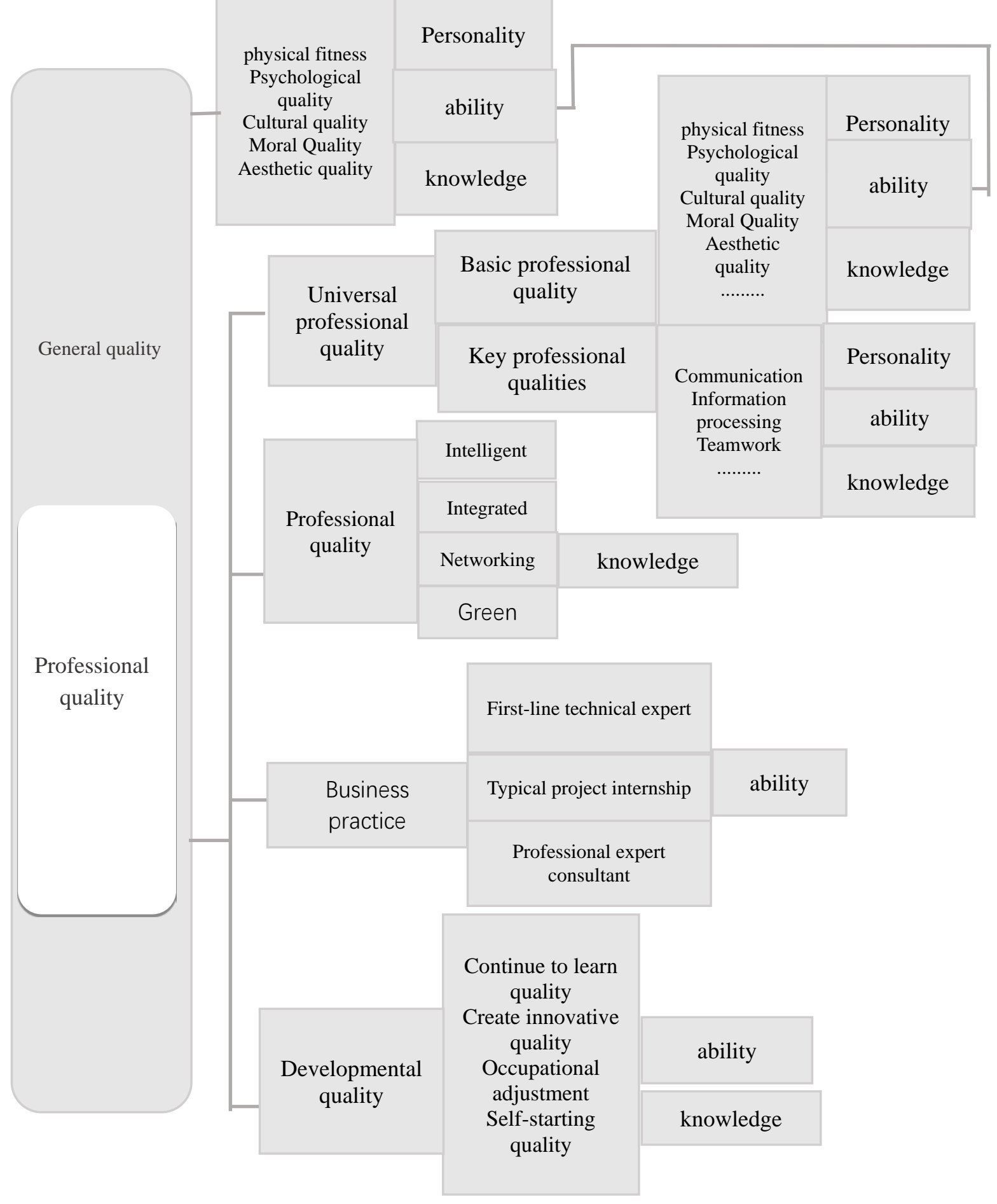

Figure 1 Performance Evaluation Structure 
The above performance evaluation system was designed, and based on the above system, 200 employed graduates who have already taken jobs in electromechanical integration were sampled to design questionnaires and analyze data samples.

Table 1 Mechatronics Professional Employment Information Table

\begin{tabular}{|c|c|c|c|c|c|}
\hline Survey item & excellent & good & medium & Below & Note \\
\hline Performance points & 17 & 105 & 73 & 15 & $\begin{array}{l}\geqq 4.0 \text { excellent, } \geqq 3.3 \text { good, } \geqq 3.0 \\
\text { medium, }<3.0 \text { Below medium }\end{array}$ \\
\hline Conduct morality & 15 & 92 & 57 & 12 & \\
\hline Humanities education & 12 & 47 & 23 & 7 & $\begin{array}{l}\text { Participate in school activities }>6 \\
\text { Or }>3 \text {, or }>1 \text {, or }=0\end{array}$ \\
\hline Corporate performance & 10 & 42 & 21 & 5 & \\
\hline $\begin{array}{c}\text { Employment enterprise } \\
\text { satisfaction }\end{array}$ & 9 & 40 & 18 & 2 & \\
\hline Employment satisfaction rate & $52 \%$ & $38 \%$ & $24 \%$ & $13 \%$ & \\
\hline
\end{tabular}

(3) Performance Analysis. According to the feedback from the survey questionnaires, among the 17 outstanding performance grade points, there were fifteen outstanding performers. Of the 15 individuals, 12 participated in school activities more than 6 times, and 9 of them achieved excellent results after employment. There were 9 people with excellent corporate satisfaction, and the employment satisfaction rate reached 52\%; There were 105 good performance grade scores, and 92 excellent performers. Of the 92 people, 37 had participated in more than 6 school activities. Of these, 32 had achieved excellent results, and those with excellent post-employment corporate satisfaction had 30 people, employment satisfaction rate reached 38\%; Among them, 5 of them have achieved excellent results, and those with excellent corporate satisfaction after employment have 12 people, employment satisfaction rate reached $13 \%$.

An important part of the performance improvement system is performance analysis. It can be seen from the above analysis that employment satisfaction is positively related to the above investigation projects, and the reform of higher vocational education has been carried out in several dimensions: curriculum design, moral quality, humanistic quality training, and corporate practice. , and to strengthen professional continuing education, to carry out multi-party evaluation in the framework of the above performance evaluation, in order to achieve the new progress of the personnel training model to deepen the transformation.

\section{Acknowledgement}

Fund Project: Guangxi Vocational Education Reform Project (GXGZJG2015A013); Wuzhou University Education Reform Project (Wyjg2016B012); Wuzhou University Key Research Project (2017B003);

\section{References}

[1] ZHANG Ying, TIAN Hongyan, Investigation and analysis of Liaoning's new countryside construction demand for talents in agricultural vocational education[J], Liaoning Education Research, 2006(8)

[2] He Zhiqiang, Research on New Mode of Talent Cultivation in Higher Vocational Education[D], Taian: Shandong Agricultural University, 2005

[3] Mao Dezhi, Research on the Development of Rural Human Resources in China [D], Wuhan: Huazhong Agricultural University, 2006 
About the Author:

Yao Jin (1982-), Male, Han Nationality, Shandong Pingyi, Master of Engineering, Associate Professor, Research Interests: Fuzzy and Neural Network Measurement and Control Technology 